\title{
Effect of thoracotomy and lung resection on exercise capacity in patients with lung cancer
}

\author{
A-M Nugent, I C Steele, A M Carragher, K McManus, J A McGuigan, J R P Gibbons, \\ M S Riley, D P Nicholls
}

\begin{abstract}
Background-Resection is the treatment of choice for lung cancer, but may cause impaired cardiopulmonary function with an adverse effect on quality of life. Few studies have considered the effects of thoracotomy alone on lung function, and whether the operation itself can impair subsequent exercise capacity.

Methods-Patients being considered for lung resection $(n=106)$ underwent full static and dynamic pulmonary function testing which was repeated 3-6 months after surgery $(n=53)$.
\end{abstract}

Results-Thoracotomy alone $(n=13)$ produced a reduction in forced expiratory volume in one second $\left(\mathrm{FEV}_{1}\right.$; mean (SE) $2.10(0.16)$ versus $1.87(0.15) 1 ; p<0.05)$. Wedge resection $(n=13)$ produced a nonsignificant reduction in total lung capacity (TLC) only. Lobectomy $(n=14)$ reduced forced vital capacity (FVC), TLC, and carbon monoxide transfer factor but exercise capacity was unchanged. Only pneumonectomy $(n=13)$ reduced exercise capacity by $28 \%\left(\mathbf{P V o}_{2} 23.9\right.$ (1.5) versus $17.2(1.7) \mathrm{ml} / \mathrm{min} / \mathrm{kg}$; difference $(95 \% \mathrm{CI})$ $6.72(3.15$ to 10.28$) ; p<0.01)$ and three patients changed from a cardiac limitation to exercise before pneumonectomy to pulmonary limitation afterwards.

Conclusions-Neither thoracotomy alone nor limited lung resection has a significant effect on exercise capacity. Only pneumonectomy is associated with impaired exercise performance, and then perhaps not as much as might be expected.

(Thorax 1999;54:334-338)

Keywords: lung cancer; thoracotomy; pneumonectomy; exercise testing

Despite recent advances in chemotherapy and radiotherapy, surgery offers the best prospect of cure in patients with non-metastatic lung cancer ${ }^{1}$ but the morbidity and mortality associated with thoracotomy and lung resection need to be considered for each patient. It was recognised many years ago that such surgery may result in impairment of cardiopulmonary function $^{2}$ which can reduce exercise tolerance and affect subsequent quality of life. Previous studies have shown impaired pulmonary function, ${ }^{34}$ reduced exercise capacity, ${ }^{5-8}$ and haemodynamic changes ${ }^{910}$ after surgery. Factors associated with limited or no lung resection, such as the presence of a thora- cotomy scar and deconditioning, may also affect lung function, but few such patients have been studied. ${ }^{35}$

The aim of this study was to compare the effect of different amounts of lung resection (pneumonectomy, lobectomy, and wedge resection) with thoracotomy alone on exercise capacity in patients with lung cancer.

\section{Methods}

Patients admitted for resection of known or suspected lung cancer were prospectively assessed over a four year period (1990-3) during which time 106 patients were studied. All patients gave informed consent for the study.

PROTOCOL

Each patient had a routine full clinical assessment prior to surgery including medical history and physical examination, chest radiography and resting 12 lead electrocardiography. Pulmonary function tests were performed including spirometric indices, total lung capacity (TLC) by whole body plethysmography, and carbon monoxide transfer factor (TLCO). Each patient attended for a cardiopulmonary exercise test on a treadmill. After familiarisation with the equipment ${ }^{11}$ each patient underwent a symptom limited treadmill test using either a modified Naughton or modified Bruce protocol, depending on the perceived level of fitness of the patient. The test included online measurement of respiratory gas exchangethat is, minute ventilation ( $\dot{\mathrm{V} E}$ ), oxygen consumption $\left(\dot{\mathrm{V}}_{2}\right)$ and carbon dioxide production $\left(\dot{\mathrm{V}} \mathrm{CO}_{2}\right)$. The heart rate was monitored continuously by electrocardiography (CM5 lead; Delmar Avionics) and oxygen saturation by pulse oximetry (Ohmeda). Blood pressure was recorded at three minute intervals throughout the test and at peak exercise using mercury syphgmomanometry. After completion of the test, patients were asked to rate their perceived level of exertion by means of a Borg score ${ }^{12}$ on a scale of $0-10$ where 0 was the lowest level of exertion and 10 the highest.

Between three and six months after surgery each patient was contacted and invited to return for a repeat treadmill exercise test and pulmonary function tests. Case records for each patient were reviewed, in particular for details of surgery, diagnosis, length of hospital stay, and postoperative outcome. Cardiopulmonary complications and deaths occurring within 30 days of surgery were identified.

MEASUREMENT OF GAS EXCHANGE

Ventilation was measured using a vane turbine placed on the inspiratory side of a non-
10 November 1998

Accepted for publication
11 December 1998 
Table 1 Number of patients assessed preoperatively and postoperatively and type of surgery performed

\begin{tabular}{lcl}
\hline & $\begin{array}{l}\text { Preoperative } \\
\text { tests }\end{array}$ & $\begin{array}{l}\text { Postoperative } \\
\text { tests }\end{array}$ \\
\hline Pneumonectomy & 18 & 13 \\
Lobectomy (1/2 lobes) & $18 / 3$ & $11 / 3$ \\
Wedge & 18 & 13 \\
Thoracotomy & 20 & 13 \\
No surgery & 21 & - \\
Others & 8 & - \\
Total & 106 & 53 \\
\hline
\end{tabular}

rebreathing respiratory valve circuit and ventilometer (PK Morgan Ltd.) ${ }^{11}$ Expired gas was collected in a mixing chamber and sampled continuously to allow measurement of expired oxygen and carbon dioxide concentrations by paramagnetic and infrared analysers, respectively (PK Morgan Ltd). The outputs from the ventilometer and gas analysers were fed via an analogue-to-digital converter to an Amstrad computer to allow calculation of ventilation rate, oxygen consumption, and carbon dioxide production. $\mathrm{PV}_{\mathrm{O}_{2}}$ was taken as the highest 15 seconds mean value of $\dot{\mathrm{V}}_{2}$ calculated by the computer in the final minute of exercise. Respiratory exchange ratios (RER) were also calculated during exercise using the formula: $\mathrm{RER}=\dot{\mathrm{V}} \mathrm{CO}_{2} / \dot{\mathrm{V}}_{2}$. Calibration of the turbine and analysers was performed before each test.

All test results were subsequently examined independently by a single experienced observer (MSR) who was not aware of the identity of the subject or of whether the test was preoperative or postoperative. The test was categorised as either maximal (cardiac limitation), maximal (pulmonary limitation), or inconclusive (submaximal). Pulmonary limitation was defined as the presence of three of the following criteria: desaturation on oximetry of $3 \%$ or more; stopped by dyspnoea rather than fatigue or pain; exceeded $80 \%$ of predicted maximal voluntary ventilation $\left(40 \times \mathrm{FEV}_{1}\right)$; or respiratory exchange ratio at peak exercise of $<1 .^{13}$

\section{STATISTICAL ANALYSIS}

Statistical analysis was performed using two way analysis of variance with repeated measures as appropriate. Bonferroni's method was used for post hoc comparisons. A p value of less than 0.05 was regarded as significant. Results are expressed as mean (SE) and differences between groups (tables 3-6) include the 95\% confidence interval (CI) of the difference.

\section{Results}

One hundred and six patients were initially assessed and performed a treadmill exercise test but 29 patients were then excluded from the study, 21 because they did not have surgery as the lung tumour was found to be inoperable on completion of investigations or the patient was considered medically unfit; three who had other surgery (plication of the diaphragm in two cases and pleurectomy in one); and five for

Table 2 Mean (SE) clinical characteristics, preoperative pulmonary function, and exercise test results in each surgical group

\begin{tabular}{|c|c|c|c|c|}
\hline & Pneumonectomy $(n=18)$ & Lobectomy $(n=21)$ & Wedge resection $(n=18)$ & Thoracotomy $(n=20)$ \\
\hline Age (years) & $61.4(2.4)$ & $64.3(1.7)$ & $64.1(2.0)$ & $61.2(2.0)$ \\
\hline Weight $(\mathrm{kg})$ & $72.2(3.7)$ & $65.8(1.8)$ & $70.8(5.1)$ & $65.2(3.2)$ \\
\hline $\mathrm{FEV}_{1}(\mathrm{l})$ & $2.29(0.17)$ & $2.05(0.11)$ & $1.96(0.14)$ & $2.01(0.12)$ \\
\hline $\mathrm{FEV}_{1}(\%$ predicted $)$ & $81.8(4.3)$ & $81.1(3.5)$ & $77.7(3.6)$ & $70.9(3.5)$ \\
\hline FVC (1) & $3.33(0.22)$ & $3.08(0.12)$ & $2.97(0.20)$ & $3.07(0.17)$ \\
\hline FVC (\% predicted) & $94.0(4.5)$ & $94.2(2.2)$ & $92.4(3.2)$ & $85.2(3.0)$ \\
\hline TLC (1) & $5.85(0.40)(\mathrm{n}=12)$ & $5.47(0.33)(\mathrm{n}=14)$ & $5.50(0.35)(\mathrm{n}=11)$ & $5.59(0.37)(\mathrm{n}=14)$ \\
\hline TLC ( $\%$ predicted $)$ & $109.1(5.8)(\mathrm{n}=12)$ & $111.5(5.6)(\mathrm{n}=14)$ & $102.5(5.5)(\mathrm{n}=11)$ & $115.2(6.0)(\mathrm{n}=14)$ \\
\hline TLCO (\% predicted) & $89.2(7.4)(\mathrm{n}=15)$ & $68.2(5.4)(\mathrm{n}=16)$ & $83.2(6.2)(\mathrm{n}=13)$ & $70.4(6.6)(\mathrm{n}=14)$ \\
\hline $\mathrm{PV} \mathrm{O}_{2}(\mathrm{ml} / \mathrm{min} / \mathrm{kg})$ & $23.7(1.2)(\mathrm{n}=17)$ & $18.2(1.3)(\mathrm{n}=21)$ & $20.4(1.9)(\mathrm{n}=18)$ & $19.9(1.3)(\mathrm{n}=20)$ \\
\hline Peak HR (beats/min) & $148(6)$ & $136(5)$ & $134(6)$ & $138(6)$ \\
\hline Peak $\dot{\mathrm{V}} \mathrm{E}(1 / \mathrm{min})$ & $57.2(4.4)$ & $47.5(3.7)$ & $47.5(5.6)$ & $48.2(2.8)$ \\
\hline Peak RER & $1.09(0.03)$ & $1.10(0.04)$ & $1.04(0.04)$ & $1.07(0.03)$ \\
\hline Borg score & $4.3(0.5)$ & $3.4(0.2)$ & $3.5(0.3)$ & $3.8(0.5)$ \\
\hline Length of stay (days) & $9.4(0.6)(\mathrm{n}=16)$ & $9.7(0.5)(\mathrm{n}=17)$ & $9.2(0.8)(\mathrm{n}=18)$ & $8.9(0.6)(\mathrm{n}=20)$ \\
\hline Complications & 7 & 3 & 2 & 5 \\
\hline Deaths & 1 & 3 & 0 & 0 \\
\hline
\end{tabular}

$\overline{\mathrm{FEV}_{1}}$ = forced expiratory volume in one second; FVC = forced vital capacity; TLC = total lung capacity; TLCO = carbon monoxide transfer factor; $\mathrm{PV}_{2}=$ oxygen consumption; $\mathrm{HR}=$ heart rate; $\dot{\mathrm{V}} \mathrm{E}=$ minute ventilation; RER = respiratory exchange ratio. No significant intergroup differences were observed in any of the variables presented.

Table 3 Mean (SE) results of pulmonary function tests and exercise tests preoperatively and postoperatively following pneumonectomy $(n=13)$

\begin{tabular}{|c|c|c|c|c|}
\hline & Preoperative & Postoperative & p value & Difference $(95 \%$ CI) \\
\hline $\mathrm{FEV}_{1}(\mathrm{l})$ & $2.38(0.23)$ & $1.59(0.12)$ & $<0.01$ & $0.79(0.48$ to 1.10$)$ \\
\hline $\mathrm{FEV}_{1}(\%$ predicted $)$ & $81.3(5.4)$ & $55.2(3.0)$ & $<0.01$ & $26.1(17.9$ to 34.3$)$ \\
\hline FVC (1) & $3.48(0.28)$ & $2.25(0.14)$ & $<0.01$ & $1.22(0.85$ to 1.59$)$ \\
\hline FVC (\% predicted) & $94.3(5.6)$ & $62.1(3.2)$ & $<0.01$ & $32.2(24.1$ to 40.2$)$ \\
\hline TLC (1) & $6.07(0.38)(n=12)$ & $3.87(0.21)(\mathrm{n}=9)$ & $<0.01$ & $2.20(1.71$ to 2.68$)$ \\
\hline TLC (\% predicted) & $109.1(5.8)(\mathrm{n}=12)$ & $70.2(6.1)(\mathrm{n}=9)$ & $<0.01$ & 38.0 (31.8 to 41.2$)$ \\
\hline TLCO (\% predicted) & $93.3(10.0)(\mathrm{n}=13)$ & $63.4(5.9)(\mathrm{n}=10)$ & $<0.05$ & $29.9(13.5$ to 46.3$)$ \\
\hline $\mathrm{PV}_{\mathrm{O}_{2}}(\mathrm{ml} / \mathrm{min} / \mathrm{kg})$ & $23.9(1.5)(\mathrm{n}=12)$ & $17.2(1.7)(\mathrm{n}=13)$ & $<0.01$ & $6.72(3.15$ to 10.28$)$ \\
\hline Peak HR (beats/min) & $146(8)$ & $127(8)$ & $<0.01$ & $18.6(12.1$ to 25.1$)$ \\
\hline Peak $\dot{\mathrm{V}} \mathrm{E}(1 / \mathrm{min})$ & $58.4(5.3)$ & $43.6(3.7)$ & $<0.01$ & $14.8(7.5$ to 22.1$)$ \\
\hline Peak VंE (\% predicted) & $74.0(5.4)$ & $78.9(4.1)$ & NS & $-4.9(-17.0$ to 7.2$)$ \\
\hline Peak RER & $1.09(0.04)$ & $1.00(0.04)$ & NS & $0.09(0.01$ to 0.17$)$ \\
\hline $\mathrm{SaO}_{2}(\%)$ & $-3.31(0.61)$ & $-4.08(0.74)$ & NS & $0.77(-0.56$ to 2.10$)$ \\
\hline Borg score & $4.6(0.6)$ & $4.3(0.4)$ & NS & $0.3(-0.7$ to 1.3$)$ \\
\hline
\end{tabular}

$\mathrm{FEV}_{1}=$ forced expiratory volume in one second $\mathrm{FVC}=$ forced vital capacity; TLC = total lung capacity; TLCO = carbon monoxide transfer factor; $\mathrm{PV}_{2}=$ oxygen consumption; $\mathrm{HR}=$ heart rate; $\dot{\mathrm{VE}}=$ minute ventilation; RER = respiratory exchange ratio; $\mathrm{SaO}_{2}=$ oxygen saturation.

$\mathrm{p}$ values analysed by ANOVA with Bonferroni's correction. 
whom no case records could be found. Thus 77 patients (46 men) were included for analysis, of whom $53(69 \%)$ reattended for postoperative tests.

Table 1 shows the number of patients assessed preoperatively and postoperatively and the type of surgery performed (pneumonectomy, single or bi-lobectomy, wedge resection, or thoracotomy with no lung resection). The latter procedure was performed in 17 cases where the tumour was found to be inoperable, in two cases where no malignancy was found, and in one case where a mediastinal tumour was resected (20 in total). Of the 18 patients with tumours, 15 were central and three peripheral, and 16 had postoperative radiotherapy. Of the 13 who attended for a second test, eight had central tumours and eight received radiotherapy in the period between the two tests.

Most complications occurred in the pneumonectomy group (44\%) while most deaths were in the lobectomy group. Of the four perioperative deaths, one was due to respiratory failure following pneumonectomy and three occurred following single lobectomy (two due to pulmonary embolism and one due to pneumonia).

Table 4 Mean (SE) results of pulmonary function tests and exercise tests preoperatively and postoperatively following lobectomy $(n=14)$

\begin{tabular}{|c|c|c|c|c|}
\hline & Preoperative & Postoperative & p value & Difference $(95 \%$ CI) \\
\hline $\mathrm{FEV}_{1}(1)$ & $2.16(0.13)$ & $1.84(0.08)$ & NS & $0.31(0.02$ to 0.61$)$ \\
\hline $\mathrm{FEV}_{1}(\%$ predicted $)$ & $84.7(3.5)$ & $72.3(3.4)$ & NS & $12.4(2.5$ to 22.3$)$ \\
\hline FVC (l) & $3.13(0.17)$ & $2.68(0.14)$ & $<0.05$ & $0.46(0.17$ to 0.74$)$ \\
\hline FVC (\% predicted) & $95.7(2.6)$ & $84.4(4.2)$ & $<0.05$ & $11.4(3.9$ to 18.8$)$ \\
\hline TLC (1) & $5.65(0.52)(\mathrm{n}=9)$ & $4.48(0.35)(\mathrm{n}=10)$ & $<0.01$ & $1.17(0.62$ to 1.73$)$ \\
\hline TLC (\% predicted) & $111.7(6.3)(\mathrm{n}=9)$ & $91.5(5.6)(\mathrm{n}=10)$ & $<0.01$ & $22.0(16.6$ to 27.3$)$ \\
\hline TLCO (\% predicted $)$ & $66.7(6.6)(\mathrm{n}=10)$ & $55.4(6.6)(\mathrm{n}=11)$ & $<0.05$ & $11.2(4.1$ to 18.4$)$ \\
\hline $\mathrm{PV}^{\circ} \mathrm{O}_{2}(\mathrm{ml} / \mathrm{min} / \mathrm{kg})$ & $18.9(1.9)(n=14)$ & $17.0(1.1)(\mathrm{n}=13)$ & NS & $1.91(-0.95$ to 4.77$)$ \\
\hline Peak HR (beats/min) & $135(7)$ & $132(6)$ & NS & $3.4(-6.6$ to 13.4$)$ \\
\hline Peak $\dot{V}_{E}(1 / \mathrm{min})$ & $48.6(5.1)(n=14)$ & $41.7(1.9)(\mathrm{n}=13)$ & NS & $6.9(-3.2$ to 17.0$)$ \\
\hline Peak V̇E (\% predicted) & $61.9(3.9)(\mathrm{n}=14)$ & $64.8(3.7)(\mathrm{n}=13)$ & NS & $-2.8(-10.7$ to 5.0$)$ \\
\hline Peak RER & $1.10(0.06)(\mathrm{n}=14)$ & $1.03(0.03)(\mathrm{n}=13)$ & NS & $0.07(-0.03$ to 0.16$)$ \\
\hline $\mathrm{SaO}_{2}(\%)$ & $-2.21(0.72)(\mathrm{n}=14)$ & $-3.57(0.66)(\mathrm{n}=13)$ & NS & $1.35(0.13$ to 2.60$)$ \\
\hline Borg score & $3.4(0.2)(\mathrm{n}=14)$ & $3.8(0.4)(\mathrm{n}=13)$ & NS & $-0.4(-1.1$ to 0.4$)$ \\
\hline
\end{tabular}

$\mathrm{FEV}_{1}=$ forced expiratory volume in one second $; \mathrm{FVC}=$ forced vital capacity; TLC $=$ total lung capacity; TLCO = carbon monoxide transfer factor; $\mathrm{PVO}_{2}=$ oxygen consumption; $\mathrm{HR}=$ heart rate; $\mathrm{VE}=$ minute ventilation; $\mathrm{RER}=$ respiratory exchange ratio; $\mathrm{SaO}_{2}=$ oxygen saturation.

$\mathrm{p}$ values analysed by ANOVA with Bonferroni's correction.

Table 5 Mean (SE) results of pulmonary function tests and exercise tests preoperatively and postoperatively following wedge resection $(n=13)$

\begin{tabular}{|c|c|c|c|c|}
\hline & Preoperative & Postoperative & $p$ value & Difference $(95 \%$ CI) \\
\hline $\mathrm{FEV}_{1}(1)$ & $1.74(0.13)$ & $1.77(0.13)$ & NS & $-0.03(-0.18$ to 0.13$)$ \\
\hline $\mathrm{FEV}_{1}(\%$ predicted $)$ & $76.8(4.5)$ & $77.6(3.7)$ & NS & $-0.8(-8.9$ to 7.4$)$ \\
\hline FVC (1) & $2.69(0.22)$ & $2.69(0.19)$ & NS & $-0.01(-0.18$ to 0.17$)$ \\
\hline FVC (\% predicted) & $91.6(4.1)$ & $91.7(2.7)$ & NS & $-0.1(-8.3$ to 8.2$)$ \\
\hline TLC (1) & $4.99(0.39)(\mathrm{n}=8)$ & $4.43(0.31)(\mathrm{n}=8)$ & NS & $0.55(0.07$ to 1.04$)$ \\
\hline TLC (\% predicted) & $103.6(7.5)(\mathrm{n}=8)$ & $99.4(6.2)(\mathrm{n}=8)$ & NS & 9.9 (3.1 to 16.8$)$ \\
\hline TLCO (\% predicted $)$ & $83.8(7.8)(\mathrm{n}=10)$ & $74.4(5.1)(\mathrm{n}=9)$ & NS & $9.3(0.5$ to 18.1$)$ \\
\hline $\mathrm{PV} \mathrm{O}_{2}(\mathrm{ml} / \mathrm{min} / \mathrm{kg})$ & $17.1(1.1)$ & $18.2(1.0)$ & NS & $-1.07(-2.84$ to 0.68$)$ \\
\hline Peak HR (beats/min) & $125(7)$ & $134(6)$ & NS & $-8.8(-17.9$ to 0.2$)$ \\
\hline Peak $\dot{V}$ E $(1 / \min )$ & $39.4(4.6)$ & $41.9(4.3)$ & NS & $-2.5(-7.0$ to 1.9$)$ \\
\hline Peak VE (\% predicted) & $65.5(7.4)$ & $69.3(6.8)$ & NS & $-3.8(-15.9$ to 8.4$)$ \\
\hline Peak RER & $1.00(0.04)$ & $0.98(0.03)$ & NS & $-0.02(-0.04$ to 0.08$)$ \\
\hline $\mathrm{SaO}_{2}(\%)$ & $-3.17(1.11)(\mathrm{n}=12)$ & $-4.50(1.06)(\mathrm{n}=13)$ & NS & $1.33(-0.45$ to 3.12$)$ \\
\hline Borg score & $3.7(0.3)$ & $4.2(0.6)$ & NS & $-0.5(-1.7$ to 0.7$)$ \\
\hline
\end{tabular}

$\mathrm{FEV}_{1}=$ forced expiratory volume in one second $; \mathrm{FVC}=$ forced vital capacity; TLC $=$ total lung capacity; TLCO = carbon monoxide transfer factor; $\dot{P V}_{\mathrm{O}_{2}}=$ oxygen consumption; $\mathrm{HR}=$ heart rate; $\dot{\mathrm{VE}}=$ minute ventilation; $\mathrm{RER}=$ respiratory exchange ratio; $\mathrm{SaO}_{2}=$ oxygen saturation.

p values analysed by ANOVA with Bonferroni's correction.

Table 6 Mean (SE) results of pulmonary function tests and exercise tests preoperatively and postoperatively following thoracotomy alone $(n=13)$

\begin{tabular}{|c|c|c|c|c|}
\hline & Preoperative & Postoperative & $p$ value & Difference $(95 \%$ CI) \\
\hline $\mathrm{FEV}_{1}(\mathrm{l})$ & $2.10(0.16)$ & $1.87(0.15)$ & $<0.05$ & $0.23(0.08$ to 0.38$)$ \\
\hline $\mathrm{FEV}_{1}(\%$ predicted $)$ & $70.9(4.6)$ & $64.4(4.6)$ & $<0.05$ & $6.5(1.9$ to 11.2$)$ \\
\hline FVC (1) & $3.08(0.21)$ & $2.72(0.18)$ & NS & $0.36(0.05$ to 0.66$)$ \\
\hline FVC (\% predicted) & $81.9(3.8)$ & $74.6(4.3)$ & NS & $7.3(-1.1$ to 15.7$)$ \\
\hline TLC (1) & $5.35(0.40)(\mathrm{n}=9)$ & $5.23(0.34)(\mathrm{n}=8)$ & NS & $0.19(-0.61$ to 0.84$)$ \\
\hline TLC (\% predicted) & $124.9(7.4)(\mathrm{n}=9)$ & $127.4(14.6)(\mathrm{n}=8)$ & NS & $-1.0(-22.7$ to 20.6$)$ \\
\hline TLCO (\% predicted) & $76.3(11.1)(\mathrm{n}=9)$ & $65.3(8.8)(\mathrm{n}=7)$ & NS & $11.0(-4.6$ to 26.6$)$ \\
\hline $\mathrm{PV}^{\circ} \mathrm{O}_{2}(\mathrm{ml} / \mathrm{min} / \mathrm{kg})$ & $20.0(1.8)(\mathrm{n}=13)$ & $17.6(1.1)(\mathrm{n}=12)$ & NS & $2.36(-0.74$ to 5.46$)$ \\
\hline Peak HR (beats/min) & $133(7)$ & $134(7)$ & NS & $-0.9(-10.1$ to 8.2$)$ \\
\hline Peak $\dot{V}_{E}(1 / \min )$ & $47.8(3.3)(\mathrm{n}=13)$ & $44.4(3.5)(\mathrm{n}=12)$ & NS & $3.5(-2.4$ to 9.4$)$ \\
\hline Peak V̇E (\% predicted) & $69.3(4.9)(\mathrm{n}=13)$ & $67.2(5.0)(\mathrm{n}=12)$ & NS & $2.1(-6.1$ to 10.3$)$ \\
\hline Peak RER & $1.05(0.04)(\mathrm{n}=13)$ & $1.02(0.02)(\mathrm{n}=12)$ & NS & $0.03(-0.07$ to 0.12$)$ \\
\hline $\mathrm{SaO}_{2}(\%)$ & $-1.50(0.44)(\mathrm{n}=13)$ & $-2.42(0.47)(\mathrm{n}=12)$ & NS & $0.92(0.18$ to 1.66$)$ \\
\hline Borg score & $3.8(0.6)$ & $4.3(0.5)$ & NS & $-0.5(-1.7$ to 0.7$)$ \\
\hline
\end{tabular}

$\mathrm{FEV}_{1}=$ forced expiratory volume in one second; FVC = forced vital capacity; TLC = total lung capacity; TLCO = carbon monoxide transfer factor; $\mathrm{PV}_{2}=$ oxygen consumption; $\mathrm{HR}=$ heart rate; $\dot{\mathrm{VE}}=$ minute ventilation; RER = respiratory exchange ratio; $\mathrm{SaO}_{2}=$ oxygen saturation.

$\mathrm{p}$ values analysed by ANOVA with Bonferroni's correction. 
Table 7 Reason for stopping exercise in patients before and after lung operation

\begin{tabular}{|c|c|c|c|c|}
\hline & Cardiac & Pulmonary & Submaximal & Changed \\
\hline \multicolumn{5}{|c|}{ Thoracotomy $(\mathrm{n}=13)$} \\
\hline Preoperative & 7 & 3 & 3 & \\
\hline Postoperative & 7 & 1 & 5 & 0 \\
\hline \multicolumn{5}{|c|}{ Wedge resection $(n=13)$} \\
\hline Preoperative & 6 & 2 & 5 & \\
\hline Postoperative & 9 & 1 & 3 & 1 \\
\hline \multicolumn{5}{|c|}{ Lobectomy $(n=14)$} \\
\hline Preoperative & 12 & 0 & 2 & \\
\hline Postoperative & 9 & 0 & 5 & 0 \\
\hline \multicolumn{5}{|c|}{ Pneumonectomy $(\mathrm{n}=13)$} \\
\hline Preoperative & 10 & 2 & 1 & \\
\hline Postoperative & 6 & 3 & 4 & 3 \\
\hline
\end{tabular}

Changed $=$ from cardiac to pulmonary limitation. For definition of pulmonary limitation, see text.

Table 2 shows the clinical characteristics, including preoperative pulmonary function and exercise test results, for each surgical group. There were no significant differences between the groups with respect to age and weight. Spirometric indices and lung volumes were also similar. Patients about to undergo pneumonectomy had a slightly greater exercise capacity than the other groups studied, and a slightly greater TLCO than patients undergoing lobectomy, but the differences were not significant. There were no significant differences in perioperative complications or mortality between the four groups.

Tables 3-6 show pulmonary function tests and exercise test results preoperatively and postoperatively following pneumonectomy, lobectomy, wedge resection, and thoracotomy alone, respectively. In the pneumonectomy group (table 3 ) there was, as expected, a significant reduction in static lung volumes, as assessed by spirometric tests, with forced vital capacity (FVC) falling by $35 \%$. Exercise ventilation was also reduced and overall exercise performance impaired $\left(\mathrm{PV}_{\mathrm{O}_{2}}\right.$ reduced by $\left.28 \%\right)$. Following lobectomy (table 4) there was a smaller but still significant reduction in lung volumes (FVC down 14\%) but exercise performance was not impaired $\left(\mathrm{PV}_{2}\right.$ down only $10 \%)$. In the patients who underwent wedge resection (table 5) there was no significant change in spirometric indices or $\mathrm{PV}_{2}$, while in the thoracotomy group (table 6) there was a significant reduction in $\mathrm{FEV}_{1}$ of $11 \%$ but no significant change in FVC, TLC or $\mathrm{PV}_{2}$.

Table 7 identifies the reason for stopping exercise in all patients in whom both preoperative and postoperative exercise tests were available. Three patients changed from cardiac to pulmonary limitation after pneumonectomy, but otherwise there was no major change in pattern.

\section{Discussion}

Exercise capacity as assessed by $\mathrm{PV}_{2}$ was reduced by $28 \%$ after pneumonectomy. Previous studies have shown reductions of $16 \%,{ }^{8}$ $20 \%$, and $28 \% .{ }^{6}$ Our patients did not appear to feel more uncomfortable with the exercise, as manifest by similar preoperative and postoperative Borg scores. The peak ventilation rates were lower postoperatively but the ventilatory reserves were similar. Peak heart rate and respiratory exchange ratios were lower, reflecting the lower work load achieved. These results would suggest a ventilatory rather than circula- tory limitation to exercise, with patients stopping exercise when a similar relative level of ventilation was reached. Other studies have suggested reduced ventilatory reserve, ${ }^{6}$ reduced stroke volume index, ${ }^{10}$ and pulmonary hypertension $^{14}$ as causes of impaired exercise tolerance after pneumonectomy.

Lobectomy caused reductions in lung volumes of $15-20 \%$ which is in keeping with previous studies, ${ }^{6710}$ but exercise capacity was not impaired, whereas other studies have found small but significant reductions in $\mathrm{PV}_{2}$ after lobectomy. ${ }^{78}$ Wedge resection produced no changes in static lung measurements or in exercise capacity.

After thoracotomy alone the only effect on spirometric indices was a small reduction in $\mathrm{FEV}_{1}$, despite the fact that in 17 cases no resection was performed because of inoperable tumour. It is possible that tumour progression in the interval between the two tests could have produced some degree of airways obstruction and radiotherapy may produce initial swelling followed by fibrosis, with a corresponding decline in lung function. There was also a small and non-significant fall in exercise capacity $\left(\mathrm{PV}_{\mathrm{O}_{2}}\right)$. This could be explained in part by two additional subjects performing submaximal tests, possibly related to general debility from tumour progression. Despite the limitations inherent in interpretation of data from such ill patients, we felt that it was important to include this group as no previous study has examined the effect on exercise capacity of simply opening and closing the chest, although one study has reported the effect on lung volumes. ${ }^{3}$ The group acts as a control and thoracotomy alone is almost the equivalent of the "sham" operation in animal studies.

Appropriate assessment of patients prior to surgery is very important. As well as a technically operable tumour, the patient should be considered fit to tolerate thoracotomy and lung resection. Many studies have suggested that exercise testing with measurement of $\mathrm{PV}_{2}$ is a useful predictor of postoperative outcome, ${ }^{5}{ }^{15-19}$ although this is not a universal finding. ${ }^{20}$ Patients with $\mathrm{PV}_{2}$ less than $15-20 \mathrm{ml} / \mathrm{min} / \mathrm{kg}$ have been found to be more likely to have postoperative complications. ${ }^{822}$ The responses to a submaximal exercise load may also give useful prognostic information. ${ }^{23}$ In the present study complications were highest in patients who had a pneumonectomy, in agreement with the findings of previous studies, ${ }^{24-26}$ but there were more postoperative deaths in patients who had a lobectomy which may reflect more careful selection of fitter patients for pneumonectomy with a higher initial $\mathrm{PV}_{2}$.

In conclusion, only patients who have had a pneumonectomy have reduced exercise tolerance, with a reduction in $\mathrm{PV}_{\mathrm{O}_{2}}$ of around $28 \%$. There is no significant impairment of exercise capacity following lobectomy, wedge resection, and thoracotomy with no resection, although small changes in static pulmonary function may occur. 
We are grateful to Dr K Prasanna for help with exercise testing and to Sister E Crawford for her help with patient care

1 Pearson FG. Current status of surgical resection for lung cancer. Chest 1994;106:337-9S.

2 Cournand A, Berry FB. The effect of pneumonectomy upon cardiopulmonary function in adult patients. Ann Surg cardiopulmonary

3 Boushy SF, Billig DM, North LB, et al. Clinical course related to preoperative and postoperative pulmonary function in patients with bronchogenic carcinoma. Chest 1971; 59:383-91

4 Berend N, Woolcock AJ, Marlin GE. Effects of lobectomy on lung function. Thorax 1980;35:145-50.

5 Markos J, Mullan BP, Hillman DR, et al. Preoperative assessment as a predictor of mortality and morbidity after lung resection. Am Rev Respir Dis 1989;139:902-10.

6 Pelletier C, Lapointe L, LeBlanc P. Effects of lung resection on pulmonary function and exercise capacity. Thorax 1990; 45:497-502.

7 Bolliger CT, Jordan P, Soler M, et al. Pulmonary function and exercise capacity after lung resection. Eur Respir $\mathcal{F}$ 1996;9:415-21.

8 Larsen KR, Svendsen UG, Milman N, et al. Cardiopulmonary function at rest and during exercise after resection for bronchial carcinoma. Ann Thorac Surg 1997;64:960-4

9 Van Meighem W, Demedts M. Cardiopulmonary function after lobectomy or pneumonectomy for pulmonary neoplasm. Respir Med 1989;83:199-206.

10 Nishimura $H$, Haniuda $M$, Morimoto $M$, et al. Cardiopulmonary function after pulmonary lobectomy in patients with lung cancer. Ann Thorac Surg 1993;55:1477-84.

11 Elborn JS, Stanford CF, Nicholls DP. Reproducibility of cardiopulmonary parameters during exercise in patients with chronic cardiac failure. The need for a preliminary test. Eur Heart F 1990;11:75-81.

12 Borg G. Psychophysical bases of perceived exertion. Med Sci Sports Exerc 1982;14:377-81.

13 Wasserman K, Hansen JE, Sue DY, et al. Principles of exercise testing and interpretation. Philadelphia: Lea and Febiger, 1987 .
14 Hsia CCW, Ramanathan M, Estrera AS. Recruitment of diffusing capacity with exercise in patients after pneumondiffusing capacity with exercise in patients a
ectomy. Am Rev Respir Dis 1992;145:811-6.

15 Eugene J, Brown SE, Light RW, et al. Maximum oxygen consumption: a physiologic guide to pulmonary resection. Surg Forum 1982;33:260-2.

16 Smith TP, Kinasewitz GT, Tucker WY, et al. Exercise capacity as a predictor of post-thoracotomy morbidity. $\mathrm{Am}$ Rev Respir Dis 1984;129:730-4.

17 Bechard D, Wetstein L. Assessment of exercise oxygen consumption as preoperative cri

18 Walsh GL, Morice RC, Putnem JB, et al. Resection of lung cancer is justified in high-risk patients selected by exercise oxygen consumption. Ann Thorac Surg 1994;58:704-10.

19 Bolliger CT, Jordan P, Soler M, et al. Exercise capacity as a predictor of postoperative complications in lung resection candidates. Am f Respir Crit Care Med 1995;151:1472-80.
Colman NC, Schraufnagel DE, Rivington RN, et al. Exercise tesing in evaluation of patients for lung resection. Am Rev Respir Dis 1982;125:604-5.

21 Epstein SE, Faling J, Daly BDT, et al. Predicting complications after pulmonary resection. Preoperative exercise testing vs a multifactorial cardiopulmonary risk index. Chest 1993;104:694-700.

22 Morice RC, Peters EJ, Ryan MB, et al. Exercise testing in the evaluation of patients at high risk for complications from lung resection. Chest 1992;101:356-61.

23 Olsen GN, Weiman DS, Bolton JWR, et al. Submaximal invasive exercise testing and quantitative lung scanning in the evaluation for 1989;95:267-73.

24 Nagasaki F, Flehinger BJ, Martini N. Complications of surgery in the treatment of carcinoma of the lung. Chest 1982; 82:25-9.

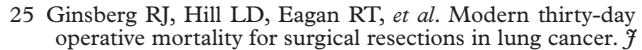
Thorac Cardiovasc Surg 1983;86:654-8.

26 Ferguson MK, Little L, Rizzo L, et al. Diffusing capacity predicts morbidity and mortality after pulmonary resection. F Thorac Cardiovasc Surg 1988;96:894-900. 